\title{
A comparison between a combination of letrozole and clomiphene citrate versus gonadotropins for ovulation induction in infertile patients with clomiphene citrate- -resistant polycystic ovary syndrome - a retrospective study
}

\author{
Serhat Ege ${ }^{1}\left(\mathbb{D}\right.$, Muhammed Hanifi Bademkıran ${ }^{1}{ }^{\mathbb{D}}$, Nurullah Peker ${ }^{2} \mathbb{D}^{\circ}$,

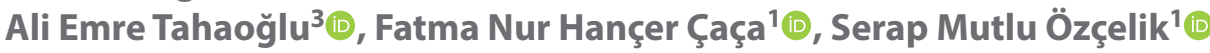 \\ ${ }^{1}$ Department of Gynecology and Obstetrics, Health Sciences University, Gazi Yasargil Training and Research Hospital, Diyarbakir, Turkey \\ ${ }^{2}$ Department of Gynecology and Obstetrics, Dicle University, Diyarbakır, Turkey \\ ${ }^{3}$ Department of Gynecology and Obstetrics, Memorial Hospital, Diyarbakir, Turkey
}

\begin{abstract}
Objectives: The aim of this study was to compare a combination treatment with CC plus letrozole versus gonadotropins in CC-resistant polycystic ovary syndrome (PCOS) patients with regard to ovulation and clinical pregnancy rate.

Material and methods: One hundred sixteen CC-resistant infertile PCOS patients were evaluated retrospectively. The patients were divided into two groups. Group $1(n=73)$ received CC plus letrozole, and Group 2 ( $n=43$ ) received gonadotropins. Results: The ovulation rate in Group 1 was $65 / 73(89 \%)$, the pregnancy rate was 13/73 (18\%), the twin foetuses rate was $1 / 73(1.3 \%)$ and the miscarriage rate was 2/73 (2.7\%). In Group 2, the ovulation rate was $41 / 43(95 \%)$, and the pregnancy rate was $8 / 43(19 \%)$ the rate of the twin foetuses was $1 / 43(2.3 \%)$ and the miscarriage rate was $1 / 43(2.3 \%)$. There was no statistically significant difference in the ovulation $(p=0.25)$, pregnancy $(p=0.91)$, twin foetuses $(p=0.89)$ and miscarriage $\mathrm{p}=0.89$ ) rates between two groups.

Conclusions: This new drug combination suggests that it may be a lower cost, lower risk alternative treatment that increases the rate of ovulation. Larger randomized clinical trials are needed to provide information on live birth rates of this combination.
\end{abstract}

Key words: polycystic ovary syndrome; gonadotropins; clomiphene resistance; letrozole; ovulation induction

Ginekologia Polska 2020; 91, 4: 185-188

\section{INTRODUCTION}

Polycystic ovary syndrome (PCOS) is a common cause of infertility and is associated with chronic anovulation and hyperandrogenaemia. PCOS affects $6 \%$ of women of reproductive age. Clomiphene citrate (CC) is considered the primary treatment for inducing ovulation in PCOS patients. CC binds to oestrogen receptors and acts as a selective oestrogen receptor modulator. As negative feedback from oestrogen decreases, gonadotropic hormones are secreted, which induces follicular growth. CC has an antiestrogenic effect and has a negative effect on endometrial thickness, which is believed to have a negative effect on pregnancy despite high ovulation [1-3].
Letrozole is another widely used oral drug for ovulation induction, with a different mechanism of action to that of CC. Letrozole inhibits androgen-oestrogen conversion, which leads to the secretion of follicle-stimulating hormone (FSH) by suppression of oestrogen production. When administered to patients with CC-resistant PCOS, letrozole induces ovulation in $54.6-84.4 \%$ of patients [4-7].

Gonadotropins can be used in case of resistance to CC and letrozole. Luteinized hormone levels may be high in CC resistant PCOS patients. Therefore, administration of exogenous gonadotropins can further increase $\mathrm{FSH}$ and luteinizing hormone levels [8]. 
The aim of this study was to compare a combination therapy with CC plus letrozole versus gonadotropins in CC-resistant PCOS patients with regard to ovulation and clinical pregnancy rate.

\section{MATERIAL AND METHODS}

The records of infertile patients who presented to the infertility polyclinic of Gazi Yaşargil Training and Research Hospital in South-Eastern Turkey between February 2017 and November 2019 were retrospectively analysed. One hundred sixteen CC-resistant infertile PCOS patients were evaluated in two groups. In Group 1 there were 73 patients who received CC + letrozole treatment, whereas Group 2 consisted of the remaining 43 patients who received gonadotropin treatment. All patients underwent ovulation induction followed by intrauterine insemination.

PCOS was diagnosed according to the Rotterdam criteria: 1) oligomenorrhoea or chronic anovulation, 2) hyperandrogenism (clinical or laboratory) and 3) polycystic ovary appearance on ultrasound [9]. CC resistance is mentioned in the absence of ovulation although $150 \mathrm{mg}$ of CC is taken for 5 days in a three-month menstrual cycle period [10].

Infertile women with PCOS diagnosed according to Rotterdam criteria (2 out of 3) Patients (infertile women) with PCOS were diagnosed according to Rotterdam criteria (2 out of 3 ) aged between of 18 and 39 years with no pathological findings (e.g. sub-mucous myomas, endometrial polyps, uterine septum, Asherman syndrome, endometriosis or hydrosalpinx) detected by ultrasonography or hysterosalpingography and normal tubal transition were included in the study. Exclusion criteria: with a body mass index (BMI) of $>30$ (we directed them to the obesity center for their weakening, due to strong insulin resistance) pregnancy; current hormonal contraceptionuse; other known cause of infertility; uncorrected thyroid disease; untreated hyperprolactinemia; medical conditions not well controlled or not recommended during pregnancy (diabetes mellitus, hypertension, endometrial hyperplasia/cancer); allergy or contraindications to letrozole, CC and gonadotropins; and male factor in fertility. Male factor infertility was defined as a sperm count of less than $15 \times 10^{6} / \mathrm{mL}$, total motility less than $40 \%$ or fewer than $4 \%$ normal forms, in accordance with the criteria of the World Health Organization [11].

The patients were divided into two groups: a CC plus letrozole group (Group 1, $n=73$ ) and a gonadotropin treatment group (Group 2, n = 43). In Group 1, the patients received a combination of $2.5 \mathrm{mg}$ of letrozole (Femara; Novartis, Basel, Switzerland) for 3 days (days of menstruation 5-7) and $100 \mathrm{mg}$ of CC (Serophene; Serono, Geneva, Switzerland) for 5 days (days of menstruation 3-7 mg) for one treatment cycle. Group 2 received recombinant follicle-stimulating hormone (rFSH) (Gonal-F 900 pen; Serono, Geneva, Switzerland) from the third day of menstruation.
Farhi et al. [12]. showed that the ideal hCG administration time in CC cycles for women with PCOS was in the 18-22 mm range. All the patients were evaluated using transvaginal ultrasonography on day 7 (the last day of CC plus letrozole administration) of menstruation or after the diameter of the largest follicle had reached $14 \mathrm{~mm}$. If a dominant follicle was present, the patients received a human chorionic gonadotropin (HCG) trigger (Ovitrelle; Serono, Geneva, Switzerland) in a single dose via subcutaneous route when the follicle size reached $18-22 \mathrm{~mm}$, followed by intrauterine insemination (IUI) 36-38 h later. Endometrial thickness was measured along the sagittal axis of the uterus between echogenic surfaces. We used a low-dose FSH regimen to minimize the risk of multiple pregnancies and ovarian hyperstimulation syndrome (OHSS. The initial daily dose of $\mathrm{rFSH}$ was set to 75 international units (IU) for 7 days from the third day of menstruation. If the follicular diameter did not exceed $9 \mathrm{~mm}$, the daily dose was increased to $37.5 \mathrm{IU}$ in the second week.

The primary outcomes were 1) ovulation, defined as a progesterone level of $>3 \mathrm{ng} / \mathrm{mL}$ between $\mathrm{D} 21$ and 23 and 2) clinical pregnancy was defined when an intrauterine gestational sac(s) was visible by ultrasonography. Secondary outcomes included a multiple pregnancy and miscarriage.

The study protocol was approved by the regional ethics committee of GaziYaşargil Training and Research Hospital (approval no: 254).

\section{Statistical analysis}

The mean \pm standard deviation (SD) were calculated for quantitative variables. Qualitative variables are presented as frequencies. The normality of the data was checked using the Kolmogorov-Smirnow test. Using an alpha value of 0.05 , the power of our study calculated at $99 \%$. The Student's t-test and Mann-Whitney U test were performed to compare continuous variables with and without a normal distribution in the two groups. The Student's t-test were performed variables with a normal distribution (Age, BMI and EMT in Tab. 1). Mann-Whitney $U$ test were performed variables without a normal distribution (Other variables in Tab. 1). The proportional data were compared using a chi-squared test and Fisher's exact test (in Tab. 2, Ovulation, Pregnancy and Follicles, $n>5$ using a chi-squared test; Miscarriage and Twin foetuses; $\mathrm{n}<5$ using a Fisher's exact test).

A $p$ value of $<0.05$ was considered significant. All statistical analyses were performed using R-software v.3.5.1 (R Statistics Software; Institute for Statistics and Mathematics, Vienna, Austria).

\section{RESULTS}

One hundred sixteen patients had CC resistant PCOS. Seventy (96\%) patients in Group 1 and 42 patients in Group 2 (98\%) developed one or more mature follicles on the day 
Table 1. Demographic and laboratory results of the patients

\begin{tabular}{|l|l|l|l|}
\hline & $\begin{array}{l}\text { Group 1 } \\
\text { CC + letrozole } \\
\text { (n= 73) }\end{array}$ & $\begin{array}{l}\text { Group 2 } \\
\text { Gonadotropins } \\
\text { (n=43) }\end{array}$ & p value \\
\hline $\begin{array}{l}\text { Age [years] } \\
\text { (mean } \pm \text { SD) }\end{array}$ & $29.54 \pm 6.68$ & $30.06 \pm 5.17$ & 0.50 \\
\hline $\begin{array}{l}\text { BMI [kg/m2] } \\
\text { (mean } \pm \text { SD) }\end{array}$ & $21.09 \pm 1.48$ & $21.46 \pm 1.61$ & 0.28 \\
\hline $\begin{array}{l}\text { E2 at HCG } \\
\text { (mean } \pm \text { SD) }\end{array}$ & $288.1 \pm 121.6$. & $285.4 \pm 127.04$ & 0.71 \\
\hline $\begin{array}{l}\text { Progesterone } \\
\text { [ng/mL] (mean } \pm \text { SD) }\end{array}$ & $12.64 \pm 7.5$ & $13.43 \pm 5.7$ & 0.62 \\
\hline $\begin{array}{l}\text { Basal E2 [pg/mL] } \\
\text { (mean } \pm \text { SD) }\end{array}$ & $46.41 \pm 12.01$ & $50.3 \pm 11.70$ & 0.81 \\
\hline $\begin{array}{l}\text { LH [IU/mL] } \\
\text { (mean } \pm \text { SD) }\end{array}$ & $5.08 \pm 1.72$ & $4.98 \pm 1.68$ & 0.85 \\
\hline $\begin{array}{l}\text { FSH [IU/mL] } \\
\text { (mean } \pm \text { SD) }\end{array}$ & $5.25 \pm 1.40$ & $5.92 \pm 1.94$ & 0.86 \\
\hline $\begin{array}{l}\text { EMT at HCG [mm] } \\
\text { (mean } \pm \text { SD) }\end{array}$ & $9.04 \pm 1.25$ & $9.24 \pm 1.13$ & 0.77 \\
\hline $\begin{array}{l}\text { Duration of infertility } \\
\text { [years] (mean } \pm \text { SD) }\end{array}$ & $3.49 \pm 0.85$ & $4.14 \pm 0.76$ & 0.05 \\
\hline Data & & & \\
\hline
\end{tabular}

Data are mean \pm standard deviation; $\mathrm{BMI}$ - body mass index; $\mathrm{CC}$ — clomiphene citrate; FSH - follicle-stimulating hormone; $\mathrm{E}_{2}$ - oestrodiol HCG - human chorionic gonadotropin; IU - international unit; LH - luteinizing hormone; Age, BMI and EMT at HCG (The Student's t-test were performed variables with a normal distribution)

Other variables (Mann-Whitney $\mathrm{U}$ test were performed variables without a normal distribution)

Table 2. Comparison of outcomes according to treatment groups

\begin{tabular}{|l|l|l|l|}
\hline & $\begin{array}{l}\text { Group 1 } \\
\text { CC + letrozole } \\
(\mathbf{n = 7 3 )}\end{array}$ & $\begin{array}{l}\text { Group 2 } \\
\text { Gonadotropins } \\
(\mathbf{n = 4 3 )}\end{array}$ & P value \\
\hline Ovulation, $\mathrm{n}(\%)$ & $65(89)$ & $41(95)$ & 0.25 \\
\hline Pregnancy, $\mathrm{n}(\%)$ & $13(18)$ & $8(19)$ & 0.91 \\
\hline Miscarraige, $\mathrm{n}(\%)$ & $2(2.7)$ & $1(2.3)$ & 0.89 \\
\hline Twin foetuses, $\mathrm{n}(\%)$ & $1(1.3)$ & $1(2.3)$ & 0.89 \\
\hline Mature Follicles & $70(96)$ & $42(98)$ & 0.96 \\
\hline$\geq 18$ mm at HCG, $\mathrm{n}(\%)$ & & & \\
\hline
\end{tabular}

Data are mean $\mathrm{n}$ (percentage)

Ovulation, pregnancy, mature follicle ( $n>5$ using a chi-squared test)

Miscarriage and twin foetuses ( $n<5$ using a Fisher's exact test)

of application of the HCG trigger. The mature follicular ratio in Group 2 [42/43 (98\%)], was higher than that in Group 1 [70/73 (96\%)], but there was no statistically significant difference between the two groups $(p=0.96)$. The ovulation rate in Group 1 was 65/73 (89\%), the pregnancy rate was $13 / 73(18 \%)$, the twin foetus rate was $1 / 73(1.3 \%)$ and the miscarriage rate was $2 / 73$ (2.7\%). In Group 2, the ovulation rate was $41 / 43(95 \%)$, and the pregnancy rate was $8 / 43(19 \%)$ the twin foetus rate was $1 / 43(2.3 \%)$ and the miscarriage rate was $1 / 43(2.3 \%)$. There was no statistically significant difference in the ovulation $(p=0.25)$, pregnancy $(p=0.91)$, twin foetuses $(p=0.89)$ and miscarriage $p=0.89$ ) rates between two groups.

\section{DISCUSSION}

Letrozole and CC have different mechanisms of action; These different mechanisms of action of the two drugs may complement each other to increase ovulation rates as compared to those achieved with gonadotropin use alone $[3,8]$. In this study, letrozole plus CC was compared with gonadotropins in CC-resistant infertile PCOS patients retrospectively. There was no statistically significant difference in the ovulation and pregnancy rates between two groups.

Previous research found no significant difference in pregnancy rates between women with CC-resistant PCOS who underwent IUI and were subsequently treated with letrozole versus those who were treated with rFSH [13]. Similarly, there was no significant difference in the pregnancy rates of women undergoing IUI who were treated with letrozole versus those treated with CC plus human menopausal gonadotropin [14]. In a retrospective study on 132 women with failed CC treatment and various causes of infertility, the cumulative pregnancy rate after three cycles of treatment with gonadotropins was higher than that after treatment with letrozole treatment [15].

There are a few published studies on the use of CC plus letrozole. In a study on 100 patients resistant to letrozole (four cycles) and CC (six cycles), Hajishafiha et al. [16] reported a follicular development rate of $82.9 \%$ (213 of 257 cycles) in patients treated with $5 \mathrm{mg}$ of letrozole plus $100 \mathrm{mg}$ of CC daily for $5 \mathrm{D}$. In the same study, patients received an FSH injection on 11 if a dominant follicle was present and received HCG trigger when the follicle was $>18 \mathrm{~mm}$ in size, followed by intrauterine insemination $36-38 \mathrm{~h}$ later. In another combination study, the patients were classified according to age and $\mathrm{BMI}$ and randomized to $2.5 \mathrm{mg}$ of letrozole $(\mathrm{n}=35)$ or combination treatment with $2.5 \mathrm{mg}$ of letrozole and $50 \mathrm{mg}$ of CC $(n=35)$ daily for 3-7 [17]. The ovulation rate in the CC + letrozole group $(27 / 35,77 \%)$ was significantly higher than that in the letrozole only group (15/35, 43\%).

In the studies by Hajishafiha et al. [16] and Mejia et al. [17], $100 \mathrm{mg}$ of CC plus $5 \mathrm{mg}$ of letrozole and $50 \mathrm{mg}$ of CC plus $2.5 \mathrm{mg}$ of letrozole were administered for 5 days, respectively. In the present study, the patients received a combination of $2.5 \mathrm{mg}$ of letrozole for 3 days (days of menstruation 5-7) and $100 \mathrm{mg}$ of CC for 5 days (days of menstruation 3-7 mg) for one treatment cycle. The aim of this treatment protocol was to determine the effect of short-term low dose letrozole use. The ovulation rate in Group 1 was 65/73 (89\%), the pregnancy rate was $13 / 73$ (18\%), In Group 2, the ovulation rate was $41 / 43$ (95\%), and the pregnancy rate was $8 / 43$ (19\%). There was no statistically significant difference in the ovulation $(p=0.25)$, pregnancy $(p=0.91)$. 
In patients treated with gonadotropins, the multiple pregnancy rate was reported to vary between 5 and 20\% [18]. In other studies, a combination of letrozole and gonadotropin in Ol cycles resulted in more mono-ovulation and a shorter ovulation induction duration [19], in addition to a reduced incidence of multiple gestations [6]. Hajishafiha et al. [16] reported five cases of twin foetuses (12\%) among patients treated with gonadotropins, whereas others reported no multiple pregnancy cases following this type of treatment [17]. Multiple gestations resulted in higher risk of preterm birth and associated neonatal morbidity and expens [20]. In our study, one patient in the gonadotropin-treatment group had a twin gestation, but this was not statistically significant.

For patients with CC resistance, gonadotropin preparations have become the first choice. Unfortunately, the use of gonadotropins is frequently complicated by the OHSS [20]. We had no case of OHSS in our study.

The present study has several limitations. First, since this study is retropective, larger prospective studies are needed, thus selection bias cannot be excluded. Second, although we increased the dose of gonadotropins, we kept the dose and duration of CC plus letrozole constant. Third, we did not study neonatal outcomes because pregnancies were not followed up to delivery. Finally, only one cycle per participant was performed (after CC resistance cycles).

\section{CONCLUSIONS}

Gonadotropins are the recommended treatment for patients with CC-resistant PCOS. However, their use necessitates serial evaluations of hormones and sonographic monitoring. This new drug combination suggests that it may be a lower cost, lower risk alternative treatment that increases the rate of ovulation. Larger randomized clinical trials are needed to provide information on live birth rates of this combination.

\section{Conflict of interest}

All the authors declare that they have no conflicts of interest.

\section{Funding}

This research received no specific grant from any funding agency in the public, commercial or not-for-profit sectors.

\section{REFERENCES}

1. Heard MJ, Pierce A, Carson SA, et al. Pregnancies following use of metformin for ovulation induction in patients with polycystic ovary syndrome. Fertil Steril. 2002; 77(4): 669-673, doi: 10.1016/s00150282(01)03266-6, indexed in Pubmed: 11937113.

2. Randall JM, Templeton A. Cervical mucus score and in vitro sperm mucus interaction in spontaneous and clomiphene citrate cycles. Fertil Steril. 1991; 56(3): 465-468, doi: 10.1016/s0015-0282(16)54541-5, indexed in Pubmed: 1894023.
3. Nakamura $\mathrm{Y}$, Ono M, Yoshida $\mathrm{Y}$, et al. Effects of clomiphene citrate on the endometrial thickness and echogenic pattern of the endometrium. Fertil Steril. 1997; 67(2): 256-260, doi: 10.1016/S0015-0282(97)81907-3, indexed in Pubmed: 9022599.

4. Holzer $\mathrm{H}$, Casper $\mathrm{R}$, Tulandi T. A new era in ovulation induction. Fertil Steril. 2006; 85(2): 277-284, doi: 10.1016/j.fertnstert.2005.05.078, indexed in Pubmed: 16595197.

5. Mitwally $M$, Casper R. Use of an aromatase inhibitor for induction of ovulation in patients with an inadequate response to clomiphene citrate. Fertil Steril. 2001; 75(2): 305-309, doi: 10.1016/s0015-0282(00)01705-2.

6. Mitwally MF, Biljan MM, Casper RF. Pregnancy outcome after the use of an aromatase inhibitor for ovarian stimulation. Am J Obstet Gynecol. 2005; 192(2): 381-386, doi: 10.1016/j.ajog.2004.08.013, indexed in Pubmed: 15695975.

7. Al-Omari WR, Sulaiman WR, Al-Hadithi N. Comparison of two aromatase inhibitors in women with clomiphene-resistant polycystic ovary syndrome. Int J Gynaecol Obstet. 2004; 85(3): 289-291, doi: 10.1016/j. ijgo.2003.11.010, indexed in Pubmed: 15145273.

8. Fritz M, Speroff L. Clinical Gyneocology endocrinology and infertility. 8th ed. L. Lippincott Williams \& Wilkins, Philadelphia 2011: 1305-1313.

9. Rotterdam ESHRE/ASRM-Sponsored PCOS Consensus Workshop Group. Revised 2003 consensus on diagnostic criteria and long-term health risks related to polycystic ovary syndrome. Fertil Steril. 2004; 81(1): 19-25, doi: 10.1016/j.fertnstert.2003.10.004, indexed in Pubmed: 14711538.

10. Beck Jl, Boothroyd C, Proctor M, et al. Oral anti-oestrogens and medical adjuncts for subfertility associated with anovulation. Cochrane Database Syst Rev. 2005(1): CD002249, doi: 10.1002/14651858.CD002249.pub3, indexed in Pubmed: 15674894.

11. World Health Organization. Laboratory manual of the WHO for the examination of human semen and sperm-cervical mucus interaction. Annali dell'Istituto superiore di sanita. ; 2001.

12. Farhi J, Orvieto $\mathrm{R}$, Gavish $\mathrm{Oz}$, et al. The association between follicular size on human chorionic gonadotropin day and pregnancy rate in clomiphene citrate treated polycystic ovary syndrome patients. Gynecol Endocrinol. 2010; 26(7): 546-548, doi: 10.3109/09513591003686312, indexed in Pubmed: 20218821.

13. Ganesh A, Goswami SK, Chattopadhyay R, et al.Comparison of letrozole with continuous gonadotropins and clomiphene-gonadotropin combination for ovulation induction in 1387 PCOS women after clomiphene citrate failure: a randomized prospective clinical trial. J Assist Reprod Genet. 2009; 26(1): 19-24, doi: 10.1007/s10815-008-9284-4, indexed in Pubmed: 19127427.

14. Jee BC, Ku SY, Suh CS, et al. Use of letrozole versus clomiphene citrate combined with gonadotropins in intrauterine insemination cycles: a pilot study. Fertil Steril. 2006; 85(6): 1774-1777, doi: 10.1016/j.fertnstert.2006.02.070, indexed in Pubmed: 16677640.

15. Quintero RB, Urban R, Lathi RB, et al. A comparison of letrozole to gonadotropins for ovulation induction, in subjects who failed to conceive with clomiphene citrate. Fertil Steril. 2007; 88(4): 879-885, doi: 10.1016/j. fertnstert.2006.11.166, indexed in Pubmed: 17920403.

16. Hajishafiha M, Dehghan M, Kiarang N, et al. Combined letrozole and clomiphene versus letrozole and clomiphene alone in infertile patients with polycystic ovary syndrome. Drug Des Devel Ther. 2013; 7: 1427-1431, doi: 10.2147/DDDT.S50972, indexed in Pubmed: 24348019.

17. Mejia RB, Summers KM, Kresowik JD, et al. A randomized controlled trial of combination letrozole and clomiphene citrate or letrozole alone for ovulation induction in women with polycystic ovary syndrome. Fertil Steril. 2019; 111(3): 571-578.e1, doi: 10.1016/j.fertnstert.2018.11.030, indexed in Pubmed: 30683591.

18. Fauser BC, Devroey P, Macklon NS. Multiple birth resulting from ovarian stimulation for subfertility treatment. Lancet. 2005; 365(9473): 1807-1816, doi: 10.1016/S0140-6736(05)66478-1, indexed in Pubmed: 15910954.

19. Ozdemir U, Ozaksit G, Cakir Gungor AN, et al. Letrozole usage adjuvant to gonadotropins for ovulation induction for patients with clomiphene citrate failure. Arch Gynecol Obstet. 2013; 288(2): 445-448, doi: 10.1007/s00404-013-2780-5, indexed in Pubmed: 23471549.

20. Diamond MP, Legro RS, Coutifaris C, et al. National Institute of Child Health and Human Development (NICHD) Reproductive Medicine Network. Assessment of multiple intrauterine gestations from ovarian stimulation (AMIGOS) trial: baseline characteristics. Fertil Steril. 2015; 103(4): 962-973.e4, doi: 10.1016/j.fertnstert.2014.12.130, indexed in Pubmed: 25707331. 